\title{
Theaflavin-3, 3 '-digallate decreases human ovarian carcinoma OVCAR-3 cell-induced angiogenesis via Akt and Notch-1 pathways, not via MAPK pathways
}

\author{
YING GAO ${ }^{1,2}$, GARY O. RANKIN ${ }^{3}$, YOUYING TU ${ }^{1}$ and YI CHARLIE CHEN ${ }^{2}$ \\ ${ }^{1}$ Department of Tea Science, Zhejiang University, Hangzhou 310058, P.R. China; ${ }^{2}$ College of Science, Technology and \\ Mathematics, Alderson Broaddus University, Philippi, WV 26416, USA; ${ }^{3}$ Department of Pharmacology, Physiology \\ and Toxicology, Joan C. Edwards School of Medicine, Marshall University, Huntington, WV 25755, USA
}

Received September 14, 2015; Accepted October 23, 2015

DOI: $10.3892 / \mathrm{ijo} .2015 .3257$

\begin{abstract}
Theaflavin-3, 3'-digallate (TF3) is a black tea polyphenol produced from polymerization and oxidization of the green tea ployphenols epicatechin gallate and (-)-epigallocatechin-3-gallate (EGCG) during fermentation of fresh tea leaves. TF3 has been reported to have anticancer properties. However, the effect of TF3 on tumor angiogenesis and the underlying mechanisms are not clear. In the present study, TF3 was verified to inhibit tumor angiogenesis. Compared with EGCG, TF3 was more potent. TF3 inhibited human ovarian carcinoma OVCAR-3 cell-induced angiogenesis in human umbilical vein endothelial cell model and in chick chorioallantoic membrane model. TF3 reduced tumor angiogenesis by downregulating HIF-1 $\alpha$ and VEGF. One of the mechanisms was TF3 inactivated $\mathrm{Akt} / \mathrm{mTOR} / \mathrm{p} 70 \mathrm{~S} 6 \mathrm{~K} / 4 \mathrm{E}-\mathrm{BP} 1$ pathway and $\mathrm{Akt} / \mathrm{c}-\mathrm{Myc}$ pathway. Besides, TF3 suppressed the cleavage of Notch-1, subsequently decreased the expression of c-Myc, HIF-1 $\alpha$ and VEGF, and finally the impaired cancer cells induced angiogenesis. Nevertheless, TF3 did not have any influence on
\end{abstract}

Correspondence to: Dr Yi Charlie Chen, College of Science, Technology and Mathematics, Alderson Broaddus University, 101 College Hill Drive Philippi, WV 26416, USA

E-mail: chenyc@ab.edu

Dr Youying Tu, Department of Tea Science, Zhejiang University, 866 Yuhangtang Road, Hangzhou 310058, P.R. China

E-mail: youytu@zju.edu.cn

Abbreviations: CAM, chick chorioallantoic membrane; DAPT, N-[N(3,5-difluorophenacetyl)-L-alanyl]-S-phenylglycine t-butyl ester; 4E-BP1, eukaryotic initiation factor 4E-binding protein-1; FBS, fetal bovine serum; HUVEC, human umbilical vein endothelial cell; HIF-1 $\alpha$, hypoxia-inducible factor $1 \alpha$; JNK, c-Jun N-terminal kinases; MAPK, mitogen-activated protein kinase; p70S6K, p70S6 kinase; mTOR, mammalian target of rapamycin; RLU, relative luminescence units; SEM, standard error of mean; NICD, Notch-1 intracellular domain; VEGF, vascular endothelial growth factor

Key words: theaflavin-3, 3'-digallate, tumor angiogenesis, Akt pathway, c-Myc, Notch-1 pathway the MAPK pathways. Taken together, these findings suggest that TF3 might serve as a potential anti-angiogenic agent for cancer treatment.

\section{Introduction}

Epithelial ovarian cancer is the most lethal gynecological cancer (1). Cytoreductive surgery with chemotherapy is the standard of care for ovarian cancer (2). However, 20-40\% of patients do not respond to first-line chemotherapy (3). Furthermore, a large proportion of patients will have a relapse of the disease within 5 years (1), especially those in advanced stage. Unfortunately, recurrence is typically less responsive to current chemotherapeutic strategies (1).

Angiogenesis plays an important role in the growth and progression of solid tumors (4). Tumor angiogenesis is characterized by the formation of new irregular blood vessels from a preexisting vascular network (5). Tumor vasculature usually has poor blood flow and high vascular permeability, which may lead to decreased efficiency of cytotoxic chemotherapy and increased potential for metastasis (6). Angiogenesis can be regulated by many signaling molecules and growth factors, including vascular endothelial growth factor (VEGF). VEGF is a crucial factor in modulating multiple vascular steps. VEGF expression can be upregulated by hypoxia-inducible factor 1 (HIF-1). HIF-1 is a basic-loop helix PER-ARNT-SIM transcription factor consisting of two subunits, HIF-1 $\alpha$ and HIF-1 $\beta$. Overexpression of HIF-1 $\alpha$ has been demonstrated in $>70 \%$ of human cancers and metastases compared to adjacent normal tissue (7). Stabilization and upregulation of HIF-1 $\alpha$ promotes the expression of VEGF by binding to HIF-responsive elements in promoters. Therefore, anti-angiogenic agents targeting HIF-1 $\alpha$ and VEGF are highlighted for anticancer treatment.

Black tea is one of the most popular beverages worldwide. Basic procedures of making black tea include withering, rolling, fermentation, and drying. During the fermentation process, green tea polyphenols are polymerized and oxidized to form oligomeric flavanols, such as theaflavins, thearubigin and other oligomers (8). Thus black tea has low tea catechin content (9). Theaflavins account for $2-6 \%$ of the dry weight of solids in brewed black tea (9). Theaflavin-3, 3'-digallate (TF3) 
(Fig. 1A) is one of the four main theaflavins in black tea, which is produced by the oxidative dimerization of epicatechin gallate (ECG) and (-)-epigallocatechin-3-gallate (EGCG). TF3 is a potent anticancer agent. It showed inhibitory effects on the growth of various human cancer cells (10). It induced apoptosis and cell cycle arrest in cancer cells by generating reactive oxygen species and/or modulating signaling pathways $(8,11,12)$. Recently, theaflavins were observed to exhibit anti-angiogenic activities. TF3 inhibited tube formation in cocultured endothelial cells with fibroblasts (13). In human prostate cancer-bearing athymic nude mice, theaflavins significantly diminished the expression of VEGF in tumors (14). Nevertheless, the mechanisms remain unclear.

In the present study, the antitumor-induced angiogenic effect and mechanisms of TF3 were investigated. TF3 impaired human ovarian carcinoma OVCAR-3 cell-induced angiogenesis. Part of the underlying mechanisms was TF3 targeted Akt/mTOR/p70S6K/4E-BP1 pathway, Akt/c-Myc pathway and Notch-1/c-Myc pathway to regulating HIF-1 $\alpha$ and VEGF expression in OVCAR-3 cells. Our study suggests that TF3 can be regarded as a candidate anti-angiogenic agent for the adjunctive therapy of cancer.

\section{Materials and methods}

Cell cultures and reagents. Human ovarian carcinoma cell line OVCAR-3, a kind gift from Dr Bing-Hua Jiang, Thomas Jefferson University, was cultured in RPMI-1640 medium (Sigma, St. Louis, MO, USA) incorporating 10\% fetal bovine serum (FBS) (Invitrogen, Grand Island, NY, USA). Human umbilical vein endothelial cells (HUVECs), purchased from American Type Culture Collection (ATCC, Manassas, VA, USA), were maintained in F-12K medium (ATCC) supplemented with 10\% FBS (Invitrogen) and Endothelial Cell Growth Kit-VEGF (ATCC). Cells were grown in a humidified incubator containing $5 \% \mathrm{CO}_{2}$ at $37^{\circ} \mathrm{C}$.

Reagents: TF3 monomer (purity: 92.4\%) was isolated and purified using previously established method (15). Wortmannin and N-[N-(3,5-difluorophenacetyl)-L-alanyl]S-phenylglycine t-butyl ester (DAPT) were purchased from Sigma and Santa Cruz Biotechnology (Santa Cruz, CA, USA), respectively. Antibodies against phospho-Akt (Ser473) (p-Akt), Akt, phospho-p70S6 kinase (Thr421/Ser424) (p-p70S6K), p70S6K, eukaryotic initiation factor 4E-binding protein-1 (4E-BP1), HIF-1 $\alpha$, Notch-1, c-Jun N-terminal kinases (JNK), p38 and phosphor-Forkhead Box O1 (Thr24) (p-FoxO1) were purchased from Cell Signaling Technology, Inc. (Danvers, MA, USA). Antibodies against phosphormammalian target of rapamycin (p-mTOR) (Ser2448), mTOR were purchased from R\&D Systems (Minneapolis, MN, USA). Antibodies against phosphor-4E-BP1 (Ser65/Thr70) (p-4E-BP1), c-Myc, phosphor-extracellular signal-regulated kinases 1/2 (Thr202/Tyr204) (p-ERK1/2), ERK1/2 and GAPDH were purchased from Santa Cruz Biotechnology Inc. (Santa Cruz). Plasmids (myrAkt delta4-129, pcDNA3-Flag mTOR wt, pWZL Neo Myr Flag RPS6KB1, pET14b PHAS-I, HA-HIF1alpha-pcDNA3, 3XFlagNICD1, pMXs-hc-MYC, ODD-Luciferase-pcDNA3, VEGF promoter, cMyc promoter (TBE1/2-wt), and pCBFRE-luc) were purchased from Addgene (Cambridge, MA, USA).
Cell viability assay. OVCAR-3 cells were seeded into 96-well plates at a density of $2 \times 10^{4}$ per well in medium with $10 \%$ FBS. After overnight growth, cells were treated with different concentrations of TF3 for $24 \mathrm{~h}$. Cell viability was measured using CellTiter $96^{\circledR}$ Aqueous One Solution Cell Proliferation assay (Promega, Madison, WI, USA), according to the manufacturer's instructions. Cell viability was expressed as a percentage compared to control cells (vehicle treatment).

HUVEC tube formation assay. Growth factor-reduced Matrigel (50 $\mu \mathrm{l}$ ) (BD Biosciences, San Jose, CA, USA) was added into each well of a 96-well plate and polymerized for $30 \mathrm{~min}$ at $37^{\circ} \mathrm{C}$. HUVECs $\left(1.5 \times 10^{4} /\right.$ well $)$ in $100 \mu \mathrm{l}$ conditioned medium (90 $\mu \mathrm{l}$ F12-K medium+10 $\mu \mathrm{l}$ cell culture supernatant of vehicle or TF3-treated OVCAR-3 cells) were seeded into each growth factor-reduced Matrigel-coated well, incubated at $37^{\circ} \mathrm{C}$ in $5 \% \mathrm{CO}_{2}$ for $6 \mathrm{~h}$, and photographed under a microscope. Tube length was quantified using the NIH ImageJ software (NIH, Bethesda, MD, USA). Tube length was expressed as a percentage compared to the control group.

Chick chorioallantoic membrane (CAM) assay. Specific pathogen-free fertile chicken eggs (Charles River Laboratories, North Franklin, CT, USA) were incubated at $37.5^{\circ} \mathrm{C}$ and slowly turned by an automatic egg turner (G.Q.F. Manufacturing Co., Savannah, GA, USA). On the 8th day of development of fertilized chicken eggs, a $1-\mathrm{cm}$ diameter window was opened in the shell of each egg to expose the CAM. On the 9th day, $10^{6}$ OVCAR-3 cells in $20 \mu \mathrm{l}$ FBS-free RPMI-1640 medium were mixed with $80 \mu 1$ Matrigel (BD Biosciences), supplemented with TF3 at a final concentration of $25 \mu \mathrm{mol} / 1(\mu \mathrm{M})$ or equivalent vehicle, and implanted onto the CAM. After incubating for another 5 days, tumor implants and blood vessels were photographed and counted for branching blood vessels. Blood vessel density was normalized to the control group.

Enzyme linked immunosorbent assays. OVCAR-3 cells were seeded into 96 -well plates at a density of $2 \times 10^{4}$ per well, incubated overnight and treated with different concentrations of TF3 for $24 \mathrm{~h}$. Cell culture supernatants were collected. The concentration of human VEGF protein was determined by a human VEGF Duo-set ELISA kit (R\&D) according to the manufacturer's instructions.

Western blot analysis. OVCAR-3 cells were treated for $24 \mathrm{~h}$ with various concentrations of TF3 in $60 \mathrm{~mm}$ dishes, and then lysed in $100 \mu \mathrm{l}$ mammalian protein extraction reagent supplemented with Halt ${ }^{\mathrm{TM}}$ Protease and Phosphatase Inhibitor Single-Use Cocktail (Life Technologies, Grand Island, NY, USA). The concentration of protein was measured using a BCA Protein assay kit (Thermo, Waltham, MA, USA). Equal amounts of protein were prepared and separated by SDS-PAGE and transferred onto the nitrocellulose membranes with a Mini-Protean 3 system (Bio-Rad, Hercules, CA, USA). The membrane was blocked with $5 \%$ non-fat milk in Tris-buffer saline containing $0.1 \%$ Tween-20 for $1 \mathrm{~h}$ at room temperature and incubated with indicated primary antibodies overnight at $4^{\circ} \mathrm{C}$ followed by horseradish peroxidase-conjugated secondary antibody for $2 \mathrm{~h}$ at $37^{\circ} \mathrm{C}$. Detection was performed by SuperSignal West Dura Extended Duration Substrate (Life 
A

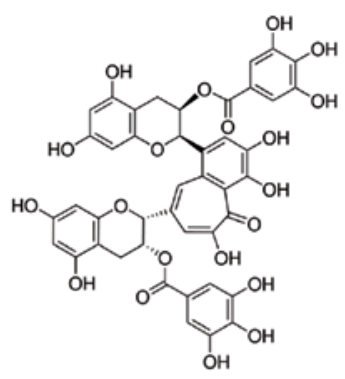

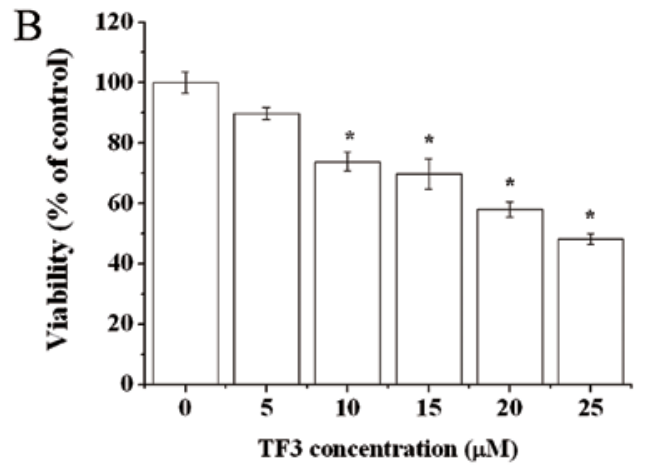

$\mathrm{D}$

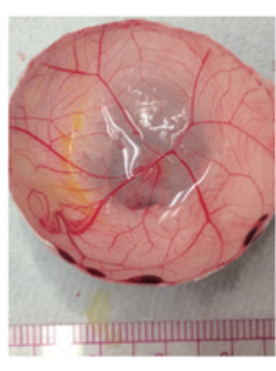

$\mathbf{0} \mu \mathbf{M}$

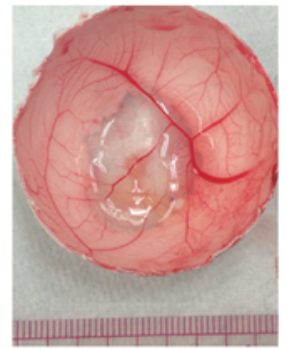

$25 \mu \mathbf{M}$
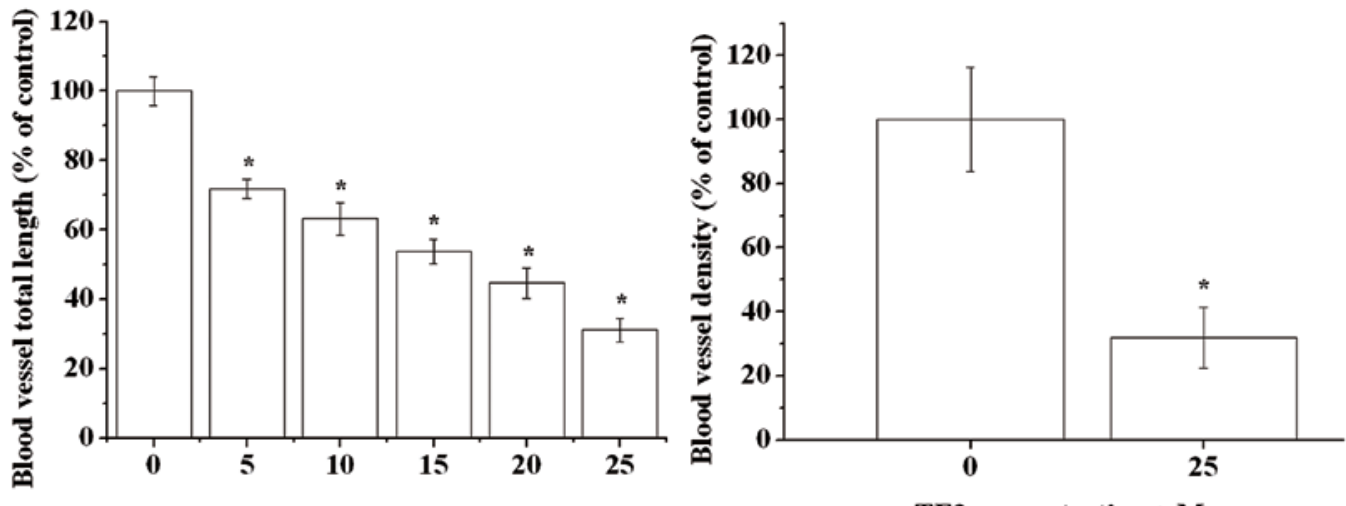

TF3 concentration $(\mu \mathrm{M})$

E

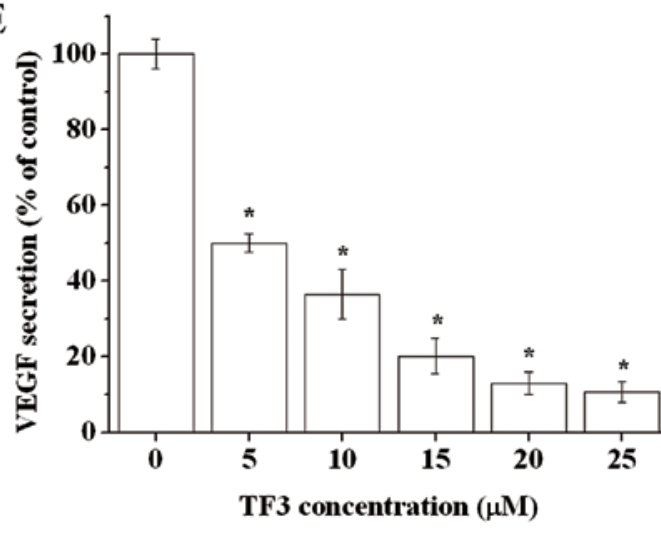

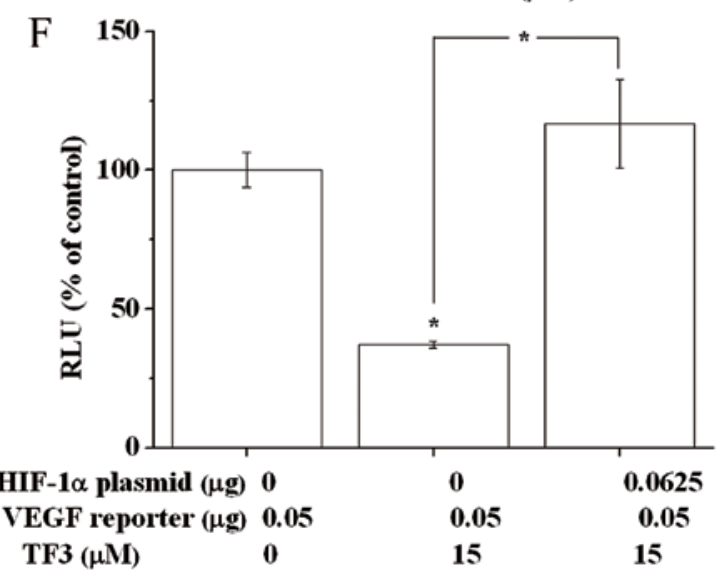

Figure 1. Theaflavin-3, 3'-digallate (TF3) inhibits OVCAR-3 cell-induced angiogenesis by targeting HIF-1 $\alpha$ and VEGF. (A) Molecular structure of TF3. (B) Viability of OVCAR-3 cells was decreased after TF3 treatment for $24 \mathrm{~h}$. (C) OVCAR-3 cells-induced HUVEC tube formation was inhibited by TF3 treatment. (D) OVCAR-3 cell-induced blood vessel development in the CAM model was reduced by TF3 treatment. (E) The protein level of VEGF in TF3treated OVCAR-3 cell culture supernatant was reduced. (F) TF3 diminished the transcriptional activity of VEGF promoter, and, overexpression of HIF-1 $\alpha$ reversed it. The data are presented as the mean \pm standard error of mean. ${ }^{*} \mathrm{P}<0.05$ compared with control or between specific groups.

Technologies) and ChemiDoc ${ }^{\mathrm{TM}}$ MP System (Bio-Rad). Protein bands were quantified with the NIH ImageJ software (NIH), normalized by corresponding GAPDH for analysis.
Transient transfection and luciferase reporter assay. OVCAR-3 cells were seeded in 96-well plates at a density of $2 \times 10^{4}$ per well and transfected with plasmids (including 


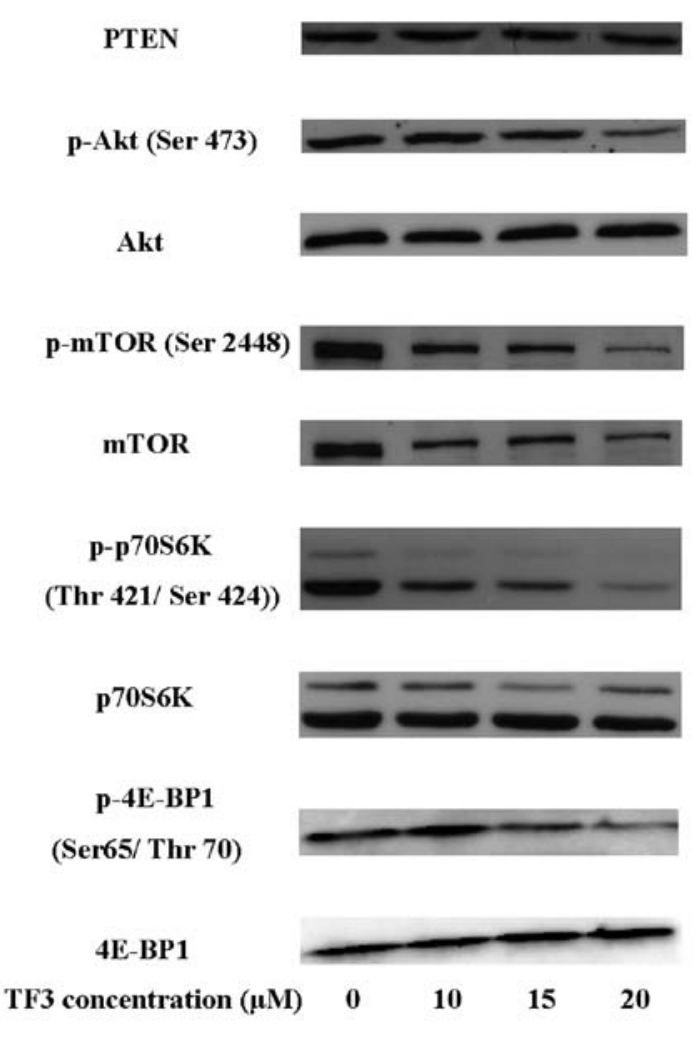

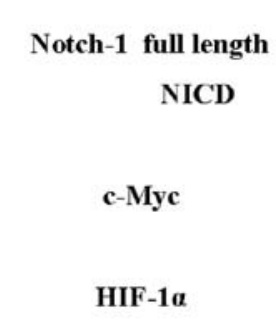

p-ERK1/2

(Thr 202/ Tyr 204)

ERK1/2

JNK

p38

p-FoxO1 (Thr24)

GAPDH

TF3 concentration $(\mu \mathrm{M})$
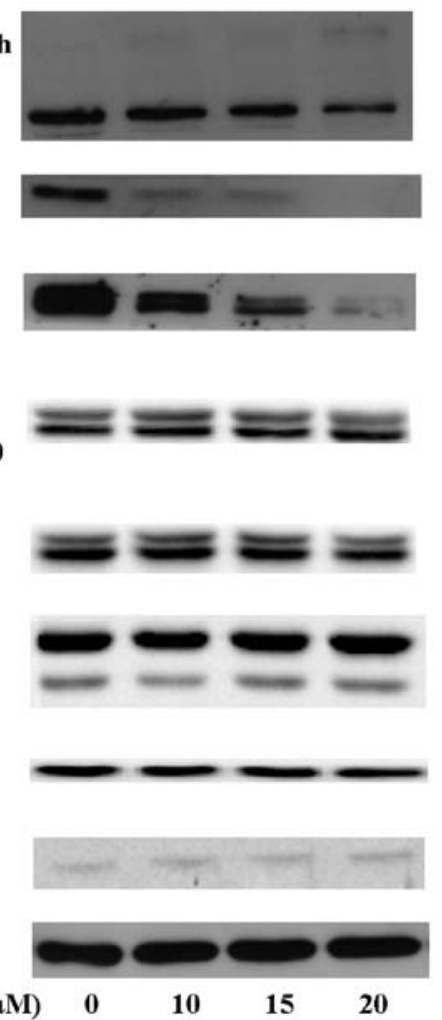

Figure 2. Angiogenesis-related proteins are affected by TF3 treatment in OVCAR-3 cells. Western blot analysis revealed that TF3 decreased the protein level of p-Akt, p-mTOR, p-p70S6K, p-4E-BP1, Notch-1 (NICD), c-Myc and HIF-1 $\alpha$ in OVCAR-3 cells. TF3 had no impact on the protein level of p-ERK1/2, ERK1/2, JNK, p38 and p-FoxO 1. GAPDH served as the loading control.

a targeted gene plasmid, a corresponding luciferase reporter plasmid and $\beta$-galactosidase control vector) using jetPrime ${ }^{\mathrm{TM}}$ DNA and siRNA Transfection reagent (VWR International, West Chester, PA, USA). Four hours later, medium was replaced by FBS-free RPMI-1640 medium containing TF3 or equivalent vehicle. Cells were incubated for another $24 \mathrm{~h}$. Luciferase assays and $\beta$-galactosidase assay were performed using One-Glo ${ }^{\text {TM }}$ luciferase assay system and $\beta$-galactosidase enzyme assay system (Promega), respectively. Luciferase activity was expressed relative to $\beta$-galactosidase activity.

Statistical analysis. The data are expressed as mean \pm standard error of mean (SEM) from at least three independent experiments. The results were analyzed with SPSS Version 18.0 for Windows (SPSS, Chicago, IL, USA) using one-way analysis of variance (ANOVA) and post hoc test (2-sided Dunnett's test) to test both overall differences and specific differences between each treatment and control. P-values $<0.05$ were considered statistically significant.

\section{Results}

TF3 reduces tumor-induced angiogenesis in vitro and in vivo by downregulating VEGF and HIF-1 $\alpha$. To evaluate the cytotoxicity of TF3 on OVCAR-3 cells, CellTiter $96^{\circledR}$ Aqueous One Solution Cell Proliferation assay was performed (Fig. 1B). TF3 treatment for $24 \mathrm{~h}$ dose-dependently inhibited the viability of OVCAR-3 cells, ranging from 100 to $48.3 \%$. The antiproliferative activity of TF3 is weak at low concentrations.
The viability of OVCAR-3 cells was $>70 \%$ when treated with concentrations of $15 \mu \mathrm{M}$ and below of TF3.

Black tea extracts, which contains theaflavins, has been reported to inhibit tumor angiogenesis. To assess whether TF3 repressed angiogenesis induced by OVCAR-3 cells, HUVEC tube formation assay was carried out. HUVECs were cultured in F12-K medium supplemented with cell culture supernatant of vehicle or TF3-treated OVCAR-3 cells. Mature, interconnected capillary-like networks were observed in the control group. However, the tube-like structures found in TF3-treated groups were less organized and leaky. Tube length was determined to quantify tube formation. The data showed TF3 interrupted OVCAR-3 cell-induced HUVEC tube formation in a dose-dependent manner (Fig. 1C).

To examine the anti-angiogenic potential of TF3 in vivo, CAM assay was conducted. Highly vascularized structure was found in the control group. TF3 treatment markedly reduced blood vessel density. These results confirmed that TF3 inhibited cancer cells induced angiogenesis in vivo (Fig. 1D).

VEGF is an important growth factor involved in tumor vascular development and maintenance. We examined the effect of TF3 on VEGF secretion using a VEGF ELISA kit. The protein level of VEGF in TF3-treated OVCAR-3 cell culture supernatant was much lower compared with that in the control group. TF3 had an excellent activity on diminishing the secretion of VEGF (Fig. 1E), indicating TF3 inhibited tumor angiogenesis by targeting VEGF.

HIF-1 $\alpha$ has a direct regulatory impact on the expression of VEGF. Western blot analysis revealed that TF3 significantly 


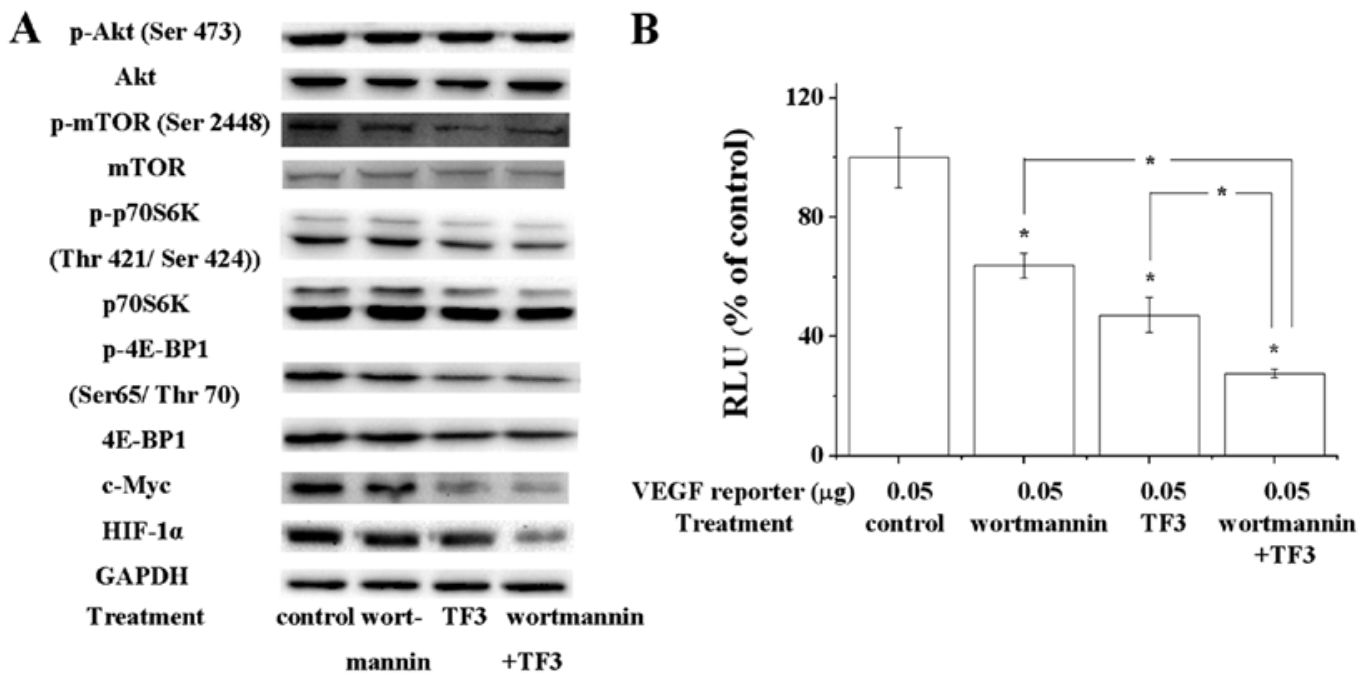

C

D

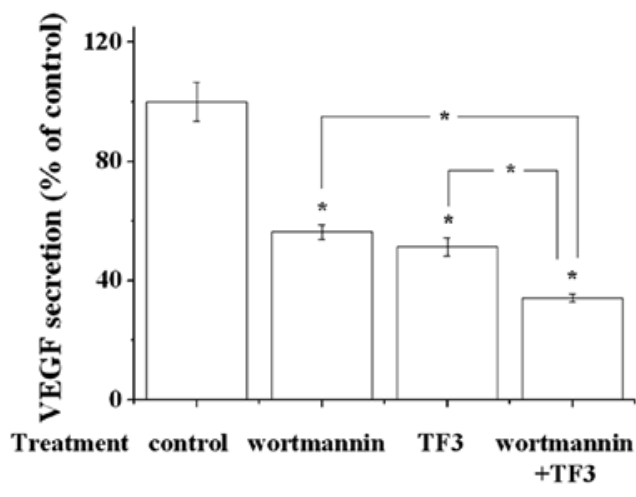

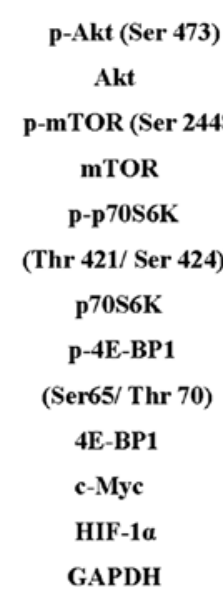

Treatment

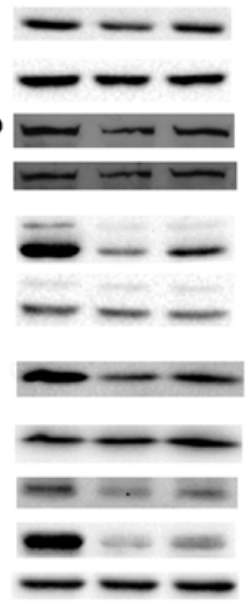

control TF3 Akt-trans

Figure 3. Akt/mTOR/p70S6k/4E-BP1 pathway and Akt/c-Myc pathway are involved in TF3-induced inhibition of HIF-1 $\alpha$ and VEGF. (A) Western blot analysis showed that $100 \mathrm{nM}$ wortmannin, $10 \mu \mathrm{M}$ TF3 and $100 \mathrm{nM}$ wortmannin $+10 \mu \mathrm{M}$ TF3 decreased the phosphorylation of Akt, mTOR, p70S6K and 4E-BP1, and expression of c-Myc and HIF-1 $\alpha$. TF3+wortmannin exhibited the strongest effect among them. GAPDH served as the loading control. (B) Luciferase reporter assay and (C) VEGF ELISA showed $100 \mathrm{nM}$ wortmannin, $10 \mu \mathrm{M}$ TF3 and $100 \mathrm{nM}$ wortmannin $+10 \mu \mathrm{M}$ TF3 suppressed the transcriptional activity of VEGF promoter and VEGF secretion, respectively. TF3+wortmannin elicited strongest effect among them. (D) Overexpression of active Akt attenuated the $15 \mu \mathrm{M}$ TF3-induced decrease of phosphorylation of Akt, mTOR, p70S6K and 4E-BP1, and expression of c-Myc and HIF-1 $\alpha$.

decreased the protein level of HIF-1 $\alpha$ in OVCAR-3 cells (Fig. 2). The data of luciferase reporter assay implied TF3 strongly eliminated the transcriptional activity of VEGF promoter. However, this inhibitory effect was abrogated by overexpression of HIF-1 $\alpha$ (Fig. 1F). It hinted TF3 downregulated VEGF by repressing HIF-1 $\alpha$ expression in OVCAR-3 cells.

TF3 inhibits HIF-1 $\alpha$ and VEGF via Akt/mTOR/p70S6K/4EBP1 pathway. Previous studies demonstrated that $\mathrm{PI}_{3} \mathrm{~K} / \mathrm{Akt}$ signaling was required for VEGF expression through HIF-1 in response to growth factor stimulation and oncogene activation (16). mTOR/p70S6K/RPS6/4E-BP1 signaling pathway also played an important role in suppressing HIF-1 $\alpha$ and VEGF expression (17). To explore whether TF3 decreased HIF-1 $\alpha$ and VEGF expression via Akt pathway, the protein levels of PTEN,
p-Akt, Akt, p-mTOR, mTOR, p-p70S6K, p70S6K, p-4E-BP1 and 4E-BP1 were detected by western blot analysis. As shown in Fig. 2, TF3 significantly lowered the protein levels of p-Akt, p-mTOR, p-p70S6K and p-4E-BP1. Whereas, the expression of PTEN, a negative regulator of the Akt pathway, was not affected by TF3 treatment. The result indicated that TF3 inactivated Akt pathway through inhibiting the phosphorylation of Akt, mTOR, p70S6K and 4E-BP1 in OVCAR-3 cells.

When treated with TF3 and wortmannin, a selective Akt pathway inhibitor, an additive inhibitory effect on Akt pathway was observed in OVCAR-3 cells. The protein levels of p-Akt, p-mTOR, p-p70S6K, p-4E-BP1, HIF-1 $\alpha$ and VEGF in TF3 and wortmannin co-treated cells were much more reduced compared with that in TF3 or wortmannin alone treated cells (Fig. 3A and C). Consistent with this, the result of luciferase reporter assay validated the transcriptional activity of VEGF 

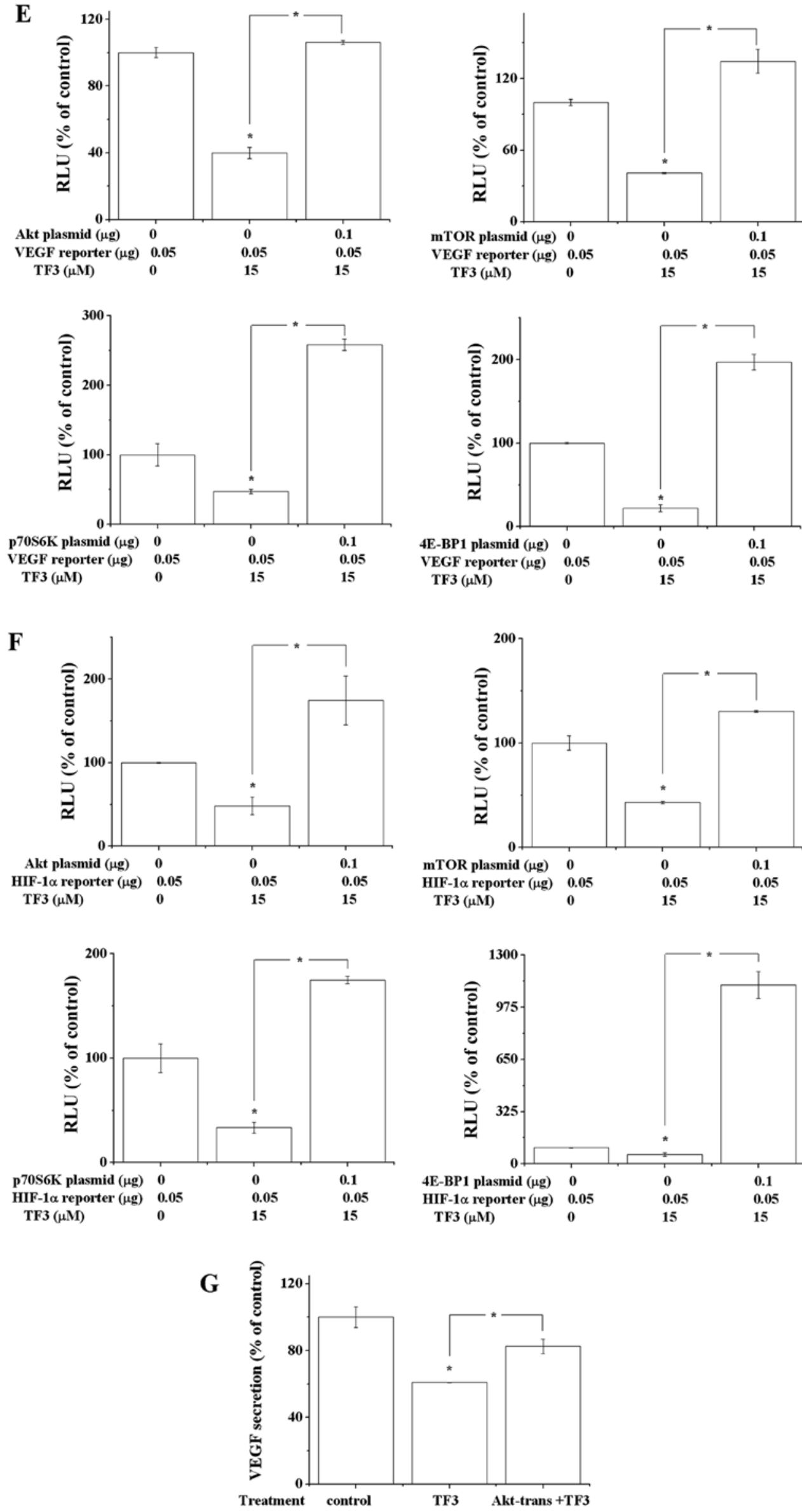

Figure 3. Continued. Overexpression of Akt, mTOR, p70S6K or 4E-BP1 attenuated TF3-induced inhibition of transcriptional activity of VEGF promoter (E) and HIF-1 $\alpha$ promoter (F). (G) Overexpression of active Akt reversed the $15 \mu \mathrm{M}$ TF3-induced reduction of VEGF secretion. The data are presented as the mean \pm standard error of mean. ${ }^{*} \mathrm{P}<0.05$ compared with control or between specific groups. 
A

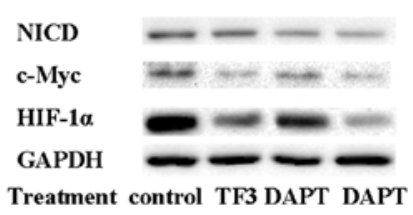

$+\mathrm{TF3}$

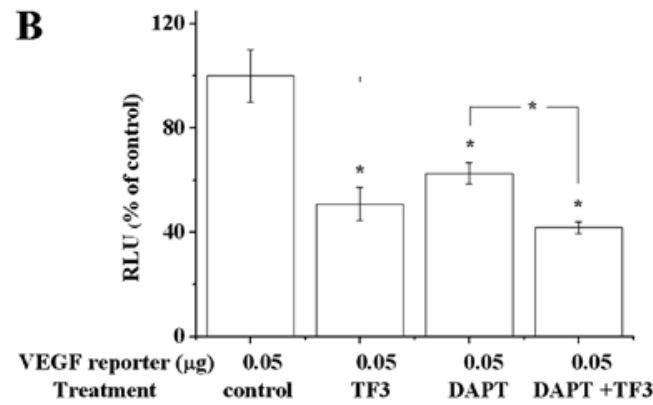

D
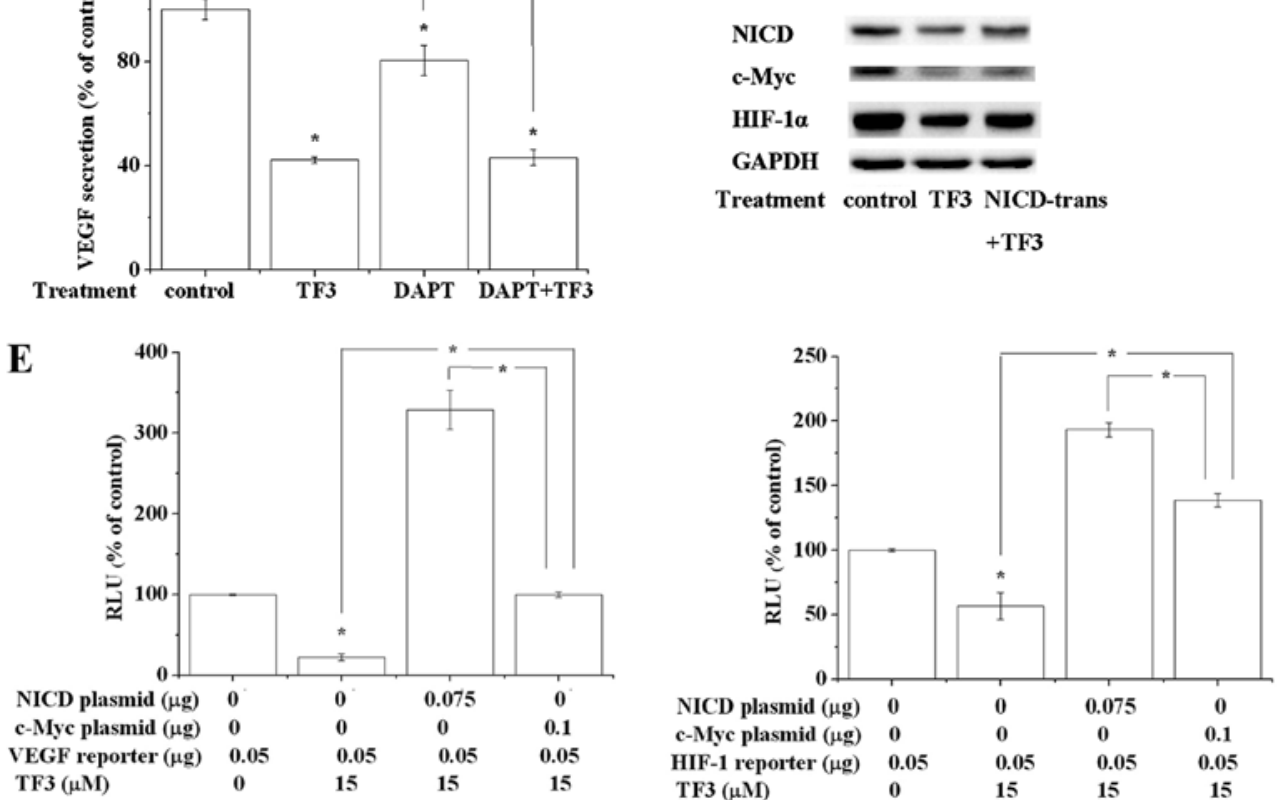

$\mathbf{F}$
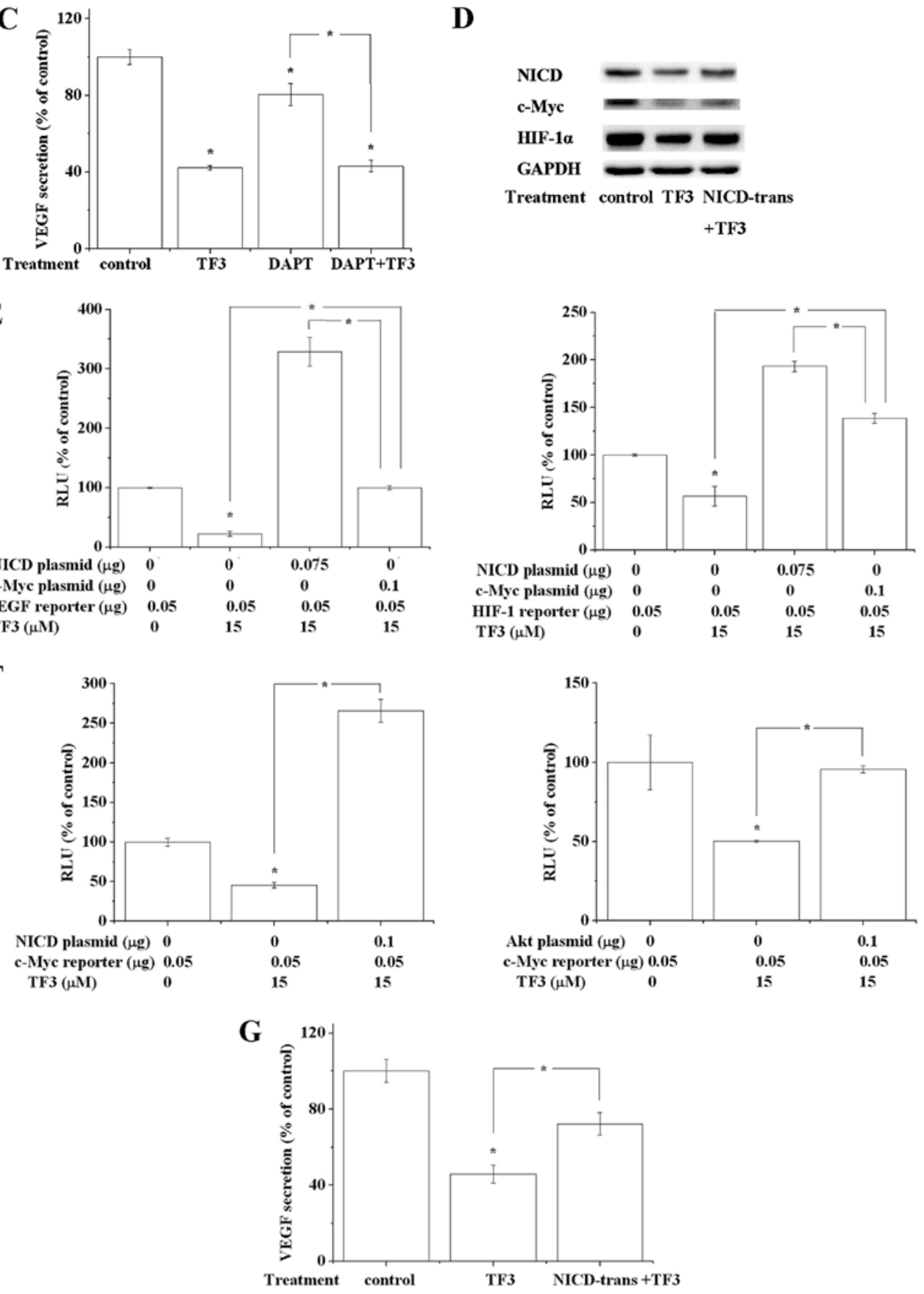

TF3 $(\mu \mathrm{M})$

Figure 4. Notch-1/c-Myc pathway is related to TF3-induced inhibition of HIF-1 $\alpha$ and VEGF. (A) Western blot analysis showed that $10 \mu \mathrm{M}$ TF3, $75 \mu \mathrm{M}$ DAPT and $10 \mu \mathrm{M} \mathrm{TF} 3+75 \mu \mathrm{M}$ DAPT decreased the expression of NICD, c-Myc and HIF-1 $\alpha$. The dose of $10 \mu \mathrm{M}$ TF3+75 $\mu \mathrm{M}$ DAPT exhibited the strongest effect. GAPDH served as the loading control. (B) Luciferase reporter assay and (C) VEGF ELISA showed $10 \mu \mathrm{M} \mathrm{TF3,} 75 \mu \mathrm{M}$ DAPT and $10 \mu \mathrm{M}$ TF3+75 $\mu \mathrm{M}$ DAPT suppressed the transcriptional activity of VEGF promoter and VEGF secretion, respectively. (D) Overexpression of NICD attenuated $15 \mu \mathrm{M}$ TF3induced decrease of NICD, c-Myc and HIF-1 $\alpha$. (E) Overexpression of NICD or c-Myc attenuated TF3-induced inhibition of transcriptional activity of VEGF promoter and HIF-1 $\alpha$ promoter. (F) Overexpression of NICD or active Akt attenuated TF3-induced inhibition of transcriptional activity of c-Myc promoter. (G) Overexpression of NICD reversed the $15 \mu \mathrm{M}$ TF3-induced reduction of VEGF secretion. The data are presented as the mean \pm standard error of mean. ${ }^{*} \mathrm{P}<0.05$ compared with control or between specific groups. 
A<smiles>O=C(O[C@H]1Cc2c(O)cc(O)cc2O[C@H]1c1ccc(O)c(O)c1)c1cc(O)c(O)c(O)c1</smiles>

C

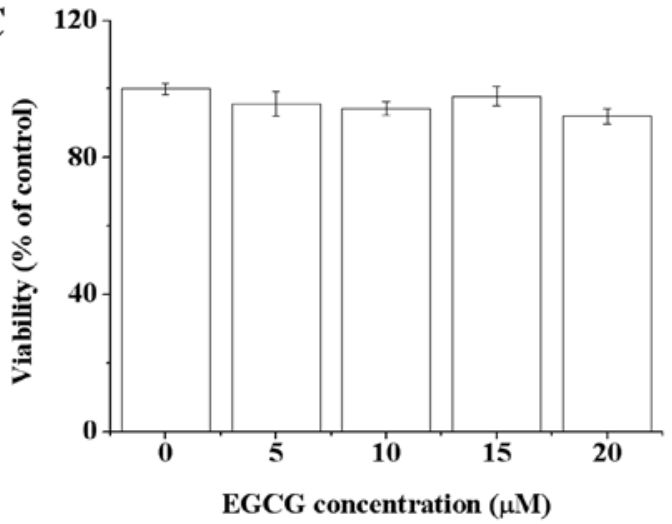

B<smiles>O=C(O[C@H]1Cc2c(O)cc(O)cc2O[C@H]1c1cc(O)c(O)c(O)c1)c1cc(O)c(O)c(O)c1</smiles>

D

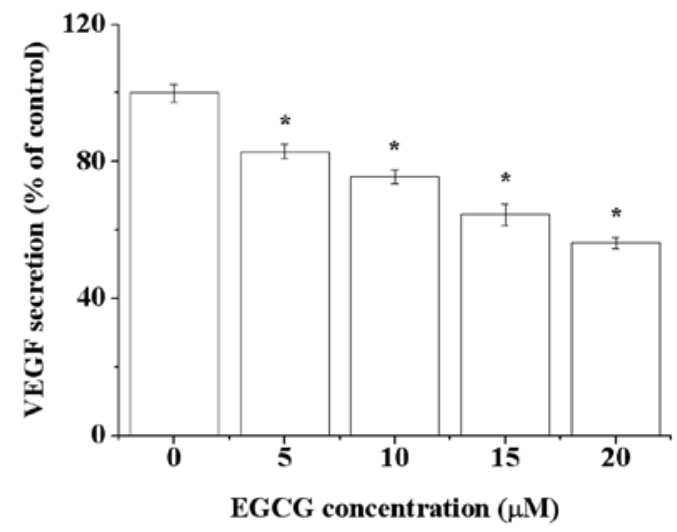

Figure 5. EGCG decreases VEGF secretion of OVCAR-3 cells. (A) Chemical structure of epicatechin gallate. (B) Chemical structure of EGCG. (C) Viability and (D) VEGF secretion of EGCG-treated OVCAR-3 cells. All data are presented as the mean \pm standard error of mean. ${ }^{*}<0.05$ compared with the control group.

promoter was lower than that in TF3 or wortmannin alone treated cells (Fig. 3B). On the contrary, transfected OCVAR-3 cells with a plasmid expressing constitutively active Akt made the cells less responsive to TF3 treatment. TF3-mediated decrease in the protein levels of p-Akt, p-mTOR, p-p70S6K, p-4E-BP1, HIF-1 $\alpha$ and VEGF was partially attenuated in Akt-overexpressing OVCAR-3 cells (Fig. 3D and G). Besides, transfected cells with plasmid expressing Akt, mTOR, p70S6K or 4E-BP1 reversed TF3-induced transcription inhibition of VEGF promoter and HIF-1 $\alpha$ promoter (Fig. 3E and F). These data provided evidence that TF3 reduced HIF- $1 \alpha$ and VEGF via Akt/mTOR/p70S6K/4E-BP1 pathway in OVCAR-3 cells.

TF3 suppresses HIF-l $\alpha$ and VEGF via Akt/c-myc and Notch-1/c-myc pathway. c-Myc is a major human oncogene which exerts many biological functions. It has been elucidated that c-Myc enhances cancer cell-mediated angiogenesis through the regulation of HIF-1 $\alpha$ (18). c-Myc expression can be regulated in an Akt-dependent manner at the level of transcription (19). c-Myc expression also can be affected by Notch-1. Notch-1 upregulates c-Myc transcription by directly binding to its promoter (20). To investigate whether Akt/c-Myc and Notch-1/c-Myc participated in tumor angiogenesis and the influence of TF3 on these pathways, western blot analysis and luciferase reporter assay were carried out. According to the results, TF3 significantly suppressed the expression of c-Myc, HIF-1 $\alpha$ and VEGF, the cleavage of Notch-1, and the phosphorylation of Akt (Figs. 1E and 2). TF3 and wortmannin co-treatment enhanced the effect of TF3 on decreasing the protein levels of c-Myc, HIF-1 $\alpha$ and VEGF (Fig. 3A and C), while overexpression of active Akt rescued it (Fig. 3D and G). Similarly, exposure to the combination of TF3 and DAPT, a Notch inhibitor, caused a stronger repression of c-Myc and HIF-1 $\alpha$ than DAPT or TF3 alone (Fig. 4A). Whereas, overexpression of Notch-1 intracellular domain (NICD) had an adverse effect on the TF3-triggered inhibition of c-Myc, HIF- $1 \alpha$ and VEGF expression (Fig. 4D and G). Luciferase reporter assay confirmed that wortmannin, DAPT and TF3 declined the transcriptional activity of VEGF promoter (Figs. 3B and 4B). On the contrary, overexpression of active Akt or NICD abrogated TF3-induced transcription inhibition of c-Myc promoter, HIF-1 $\alpha$ promoter and VEGF promoter (Figs. 3E and F, and 4E and F). Transfected cells with plasmid expressing c-Myc eliminated TF3-induced transcription inhibition of HIF-1 $\alpha$ and VEGF (Fig. 4E). Taken together, Akt/c-Myc/HIF-1 $\alpha /$ VEGF pathway and Notch-1/c-Myc/ HIF-1 $\alpha /$ VEGF pathway are involved in the antitumor angiogenic mechanisms of TF3.

TF3 does not affect HIF-1 $\alpha$ and VEGF via the MAPK pathways. MAPK pathways play essential roles in cell proliferation and differentiation. Activation of MAPK signaling pathways has been reported to participate in tumorigenesis, metastasis, and angiogenesis of multiple human malignancies (21). To investigate whether TF3 had an influence on MAPK pathways, western blot assay was carried out. In this study, TF3 showed no sign of affecting the protein levels of p-ERK1/2, ERK1/2, JNK, p38 and p-FoxO1 (Fig. 5), suggesting MAPK pathways were not relevant to the antitumor angiogenic activity of TF3. 


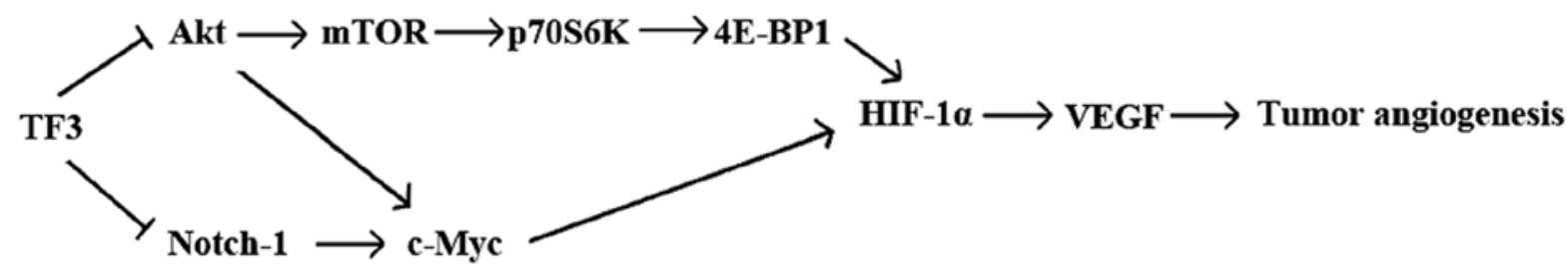

Figure 6. Proposed mechanism of inhibition of tumor angiogenesis via Akt and Notch-1 pathways.

\section{Discussion}

Ovarian cancer is one of the most common cancers in women. Due to the fact that current chemotherapies do not work on a proportion of patients and may cause severe side effect, it is critical to identify alternative strategies. Some nutrients were found to have anticancer activities with little side effect. A previous study presented that black tea consumption was associated with a linear decline in ovarian cancer risk (22). TF3 is produced in black tea manufacturing process. It has multiple biological activities, including the anti-oxidant, anti-bacterial, anti-obese, and anticancer effects. TF3 inhibits proliferation and/or induce apoptosis of various cancer cells $(11,12)$. In this study, we tested the cytotoxicity of TF3 on OVCAR-3 cells and found TF3 inhibited cell proliferation, especially at high concentrations. This is consistent with the former research that theaflavins exhibited anti-proliferative and apoptotic activity in human teratocarcinoma of ovarian origin (23). Although previous studies and the current study proved TF3 exerted an anti-proliferative effect of cancer cells, the working concentrations were much higher than the attainable concentrations of TF3 in plasma and tissues (24).

Previous studies showed that some food-derived natural compounds elicited growth inhibitory activity at higher concentrations while anti-angiogenic activity at relatively lower concentrations $(25,26)$. Tumor angiogenesis is related with poor prognosis in ovarian carcinoma (27). Cancer cells can secrete pro-angiogenic factors, including VEGF and basic fibroblast growth factor, to stimulate normal endothelial cell growth through paracrine mechanisms (28). VEGF regulates the key steps of angiogenic process, particularly endothelial cell proliferation, survival, permeability, and migration (29). TF3 has been demonstrated to inhibit gene expression of VEGF in A549 lung cancer cells (30). However, the impact of TF3 on ovarian cancer-induced angiogenesis has not been reported yet. To explore whether TF3 hampered tumor induced angiogenesis, we tested the anti-angiogenic activity of TF3 in the HUVEC model and CAM model, and the VEGF protein content in the cell culture supernatant of TF3-treated OVCAR-3 cells. In this study, TF3 was verified to block OVCAR-3 cell-triggered HUVEC tube formation and blood vessel development in the CAM model. TF3 started to inhibit HUVEC tube formation at $5 \mu \mathrm{M}$. About half of OVCAR-3 cell-induced HUVEC tube formation was blocked after $15 \mu \mathrm{M}$ TF3 treatment. The result of VEGF ELISA was in accordance with that of tube formation assay. TF3 strongly reduced the VEGF secretion of OVCAR-3 cells. Treatment with $5 \mu \mathrm{M}$ TF3 caused an $\sim 50 \%$ decline of VEGF secretion. The data implied that TF3 might exert its antitumor angiogenic function by downregulating
VEGF. It also provided evidence supporting a multifunction of TF3 on OVCAR-3 cells between different concentrations. In the present study, we also measured the effect of EGCG, a precursor of TF3, on VEGF secretion of OVCAR-3 cells. EGCG was regarded as one of the most potent bioactives in green tea and has been proven to inhibit tumor angiogenesis (31). Compared with EGCG, the working concentration of TF3 was much lower (Fig. 5D). One of the possible reasons might be that TF3 was more stable than EGCG in aqueous system (pH 7.4) (32). Structural differences might also be responsible for this (Figs. 1A and 5B). The activity of tea polyphenols is related with the number and position of hydroxyl groups in molecules (33). TF3 is produced by the oxidative dimerization of ECG and EGCG. Therefore, TF3 contains more hydroxyl groups than ECG or EGCG alone.

HIF- $1 \alpha$ is a subunit of the heterodimeric transcription factor HIF-1, which regulates the transcription of $>60$ genes, including VEGF. Dysregulation and overexpression of HIF-1 $\alpha$ are heavily implicated in cancer biology, specifically in areas of vascularization and angiogenesis. Constitutively elevated levels of HIF-1 $\alpha$ protein were detected under normal conditions in OVCAR-3 cells (16). We observed TF3 remarkably decreased the expression of HIF-1 $\alpha$ in OVCAR-3 cells. Luciferase reporter assay suggested TF3 inhibited VEGF by suppressing HIF-1 $\alpha$. EGCG has been reported to suppress breast tumor angiogenesis and growth via inhibiting the activation of HIF-1 $\alpha$ and expression of VEGF (34). Similar functions of EGCG were also found in human cervical carcinoma and hepatoma cells (35). It suggested that HIF-1 $\alpha$ /VEGF might be key therapeutic targets for tea polyphenols.

Multiple signaling pathways are involved in the regulation of HIF-1 $\alpha$ /VEGF. One of them is the Akt signaling pathway. Akt signaling pathway has been considered to participate in angiogenesis in the neoplastic and non-neoplastic process (36). Growth factors, cytokines, and other signaling molecules stimulate HIF-1 protein synthesis via activation of Akt pathway (16). The activation of Akt pathway starts from the phosphorylation of Akt. Then, mTOR can be phosphorylated and activated by Akt. Subsequently, activated mTOR regulates the phosphorylation and activation of p70S6K and 4E-BP1, two known downstream targets of mTOR (37). Active p70S6K and 4E-BP1 enhance the translation of mRNAs that bear a 5' terminal oligopyrimidine tract, which encodes proteins related with the translational apparatus like ribosomal proteins, elongation factors and the poly A-binding protein (38). In the present study, we proved TF3 markedly decreased the phosphorylation of Akt, mTOR, p70S6K, and 4E-BP1, reduced the expression of HIF-1 $\alpha$ and VEGF. This effect was potentiated by the $\mathrm{PI}_{3} \mathrm{~K} / \mathrm{Akt}$ inhibitor wortmannin 
and impaired by overexpression of active Akt. This is the first report that Akt/mTOR/p70S6K/4E-BP1/HIF-1 $\alpha / \mathrm{VEGF}$ pathway was involved in the anti-angiogenic effect of TF3. Recently, some natural compounds have been proven to inhibit HIF-1 $\alpha$ and VEGF expression by targeting Akt signaling pathway. Quercetin, a flavonol found in many fruits and vegetables, inhibited angiogenesis mediated human prostate tumor growth by targeting VEGFR-2 regulated Akt/mTOR/ p70S6K signaling pathways (39). Silibinin, a natural flavonoid extracted from the milk thistle seeds, suppressed HIF-1 $\alpha$ and $\mathrm{mTOR} / \mathrm{p} 70 \mathrm{~S} 6 \mathrm{~K} / 4 \mathrm{E}-\mathrm{BP} 1$ signaling pathway in human cervical and hepatoma cancer cells (17). Tanshinone IIA, a derivative of phenanthrene-quinone from the dried root of Salvia miltiorrhiza, regulated breast cancer growth and tumor angiogenesis via mTOR/p70S6K/RPS6/4E-BP1-mediated repression of HIF-1 $\alpha$ and VEGF expression (37). Our study was in agreement with the previous studies and suggested that Akt/mTOR/p70S6K/4E-BP1/HIF-1 $\alpha /$ VEGF pathway was an important target for plant-derived nutrients to inhibit tumor angiogenesis.

c-Myc is a transcription factor essential for vasculogenesis and angiogenesis during development and tumor progression (40). Targeting c-Myc/HIF-1 $\alpha$ pathway inhibits cancer growth and angiogenesis (41).

Akt pathway has an influence on c-Myc (19). LY294002, a $\mathrm{PI}_{3} \mathrm{~K} / \mathrm{Akt}$ inhibitor, reduced c-Myc expression and regulated the degradation of c-Myc via affecting the phosphorylation status of Thr58 (19). In this study, western blot analysis revealed that c-Myc expression and phosphorylation of Akt was greatly inhibited by TF3. Hence, we hypothesized that $\mathrm{Akt} / \mathrm{c}-\mathrm{Myc} / \mathrm{HIF}-1 \alpha$ pathway might be related to the antitumor angiogenic effect of TF3. To confirm this hypothesis, western blot and luciferase reporter assay were performed. Both TF3 and wortmannin inhibited the activation of Akt, expression of c-Myc, HIF-1 $\alpha$ and VEGF. TF3 and wortmannin combination led to a more effective suppression. Conversely, transfected cells with plasmid expressing active Akt enhanced TF3-resistance of OVCAR-3 cells. These results indicated that TF3 inhibited HIF-1 $\alpha$ and VEGF via Akt/c-Myc pathway. Akt/c-Myc pathway has been discovered to have an impact on cellular metabolism, cell proliferation and the cell cycle. Akt or c-Myc alone has been proven to regulate angiogenesis via HIF-1 $\alpha$ /VEGF pathway. In this study, Akt and c-Myc was demonstrated to be relevant in stimulating tumor angiogenesis. Akt regulated the pro-angiogenic effect of c-Myc through modulating the expression of c-Myc. Thus, we discovered a novel target pathway responsible for the anti-angiogenic activity of TF3 in OVCAR-3 cells.

Notch-1 is important upstream of c-Myc. It modulates the expression of c-Myc by directly binding to its promoter. Notch-1 is a type I transmembrane receptor. When binding to its ligands, metalloproteinase-mediated and $\gamma$-secretasemediated cleavage is induced. Subsequently, NICD is released from plasma membrane, translocated into the nucleus, and binds CBF-1/suppressor of hairless/Lag-1, mastermind-like-1, and $\mathrm{p} 300 / \mathrm{CBP}$, to form a transcriptional coactivator (42). Notch-1 is a regulator of tumor angiogenesis (43). Previous studies showed overexpression of Notch-1 promoted cell growth and tumor angiogenesis in myeloma (44). Whereas, Notch-1 antibody presents an adverse effect on tumor growth and angiogenesis (45). $\beta$-elemene, a sesquiterpene found in a variety of plants, has been demonstrated to attenuate angiogenesis capacity of $\mathrm{CD} 44^{+}$gastric cancer stem-like cells by interfering with the expression of Notch-1 (46). Notch-1 signaling is active in ovarian cancer (47). In the present study, we observed TF3 inhibited the cleavage of Notch-1. To verify whether there was a link between Notch-1/c-Myc pathway and HIF-1 $\alpha$ /VEGF pathway, DAPT, a $\gamma$-secretase inhibitor was used. According to the results, DAPT lowered the expression of NICD, c-Myc, HIF-1 $\alpha$ and VEGF. It hinted that HIF-1 $\alpha$ and VEGF were regulated by Notch-1/c-Myc pathway in OVCAR-3 cells. Further experiments revealed that TF3 promoted the repressive effect of DAPT on Notch-1/c-Myc pathway. On the contrary, overexpression of NICD hampered TF3-trigged inhibition of these proteins. Based on the above results, we concluded that TF3 downregulated HIF-1 $\alpha$ and VEGF partially by suppressing Notch-1/c-Myc pathway. The protein level of NICD in TF3 and/or DAPT treated cells was control group $>\mathrm{TF} 3$ group $>$ DAPT group $>\mathrm{TF} 3+\mathrm{DAPT}$ group, while the protein levels of $\mathrm{c}-\mathrm{Myc}$ and HIF-1 $\alpha$ were control group $>$ DAPT group $>$ TF3 group $>$ TF3+DAPT group. This inconsistence could be explained by TF3 suppressing c-Myc/ HIF-1 $\alpha$ pathway not only via Notch-1, but also other targets (for example, Akt pathway). Besides, the combination of TF3 and DAPT failed to cause an additive effect on decreasing VEGF secretion, implying Notch-1/c-Myc pathway might only play a subordinate role in the anti-angiogenic function of TF3.

MAPK pathways regulate many cellular activities, including angiogenesis. MAPKs are activated by the dual phosphorylation of neighboring threonine and tyrosine residues in response to various extracellular stimuli (48). ERK, JNK and p38 are three major groups of MAPKs. ERKs are often activated by growth signals, while JNK and p38 are often initiated by stress-responsive signaling (48). FoxO1 is a forkhead transcription factor which specifically regulates a nonredundant, but overlapping set of angiogenesis- and vascular remodeling-related genes (49). FoxO1 contains 15 consensus phosphorylation sites for the MAPK family. It has been demonstrated that ERK and p38 directly regulated the transcriptional activity of FoxO1 via phosphorylation (50). Similarly, JNK-dependent phosphorylation of FoxO proteins results in nuclear accumulation and enhanced transcriptional activity (51). In the former studies, EGCG inhibited tumor angiogenesis through inactivating ERK1/2 in human colon carcinoma cells (52) and human pancreatic tumors (53). EGCG increased the activity of p38, but not ERK 1/2 in OVCAR-3 cells (54). In HUVECs, inhibition of $\mathrm{PI}_{3} \mathrm{~K} / \mathrm{AKT}$ and MEK/ ERK pathways enhanced the anti-angiogenic effects of EGCG through activation of FoxO transcription factors (48). However, we did not observe any effect of TF3 on ERK1/2, JNK or p38 in this case. This result implicated that although TF3 and EGCG shared some anti-angiogenic targets, they had their specific targets. This might be related to their molecular structures. TF3 possesses a benzotropolone skeleton that is formed from co-oxidation of EGCG and ECG, one with a vic-trihydroxy moiety and the other with an ortho-dihydroxy structure (9). The benzotropolone moiety has been proven to be important in the antioxidant activity (55), anti-inflammatory activity (56), anti-peptide transport activity and activating AMP-activated protein kinase (57). Thus, we speculated that 
benzotropolone moiety might also be vital for its anticancer activity. Quantitative structure-activity relationship analysis should be carried out to investigate this assumption.

In conclusion, this study presented that TF3 had the ability to inhibit ovarian cancer cell-induced angiogenesis in vitro and in vivo. TF3 exerted this effect through suppression of HIF-1 $\alpha$ and VEGF. One of the mechanisms is that TF3 inhibited Akt/ $\mathrm{mTOR} / \mathrm{p} 70 \mathrm{~S} 6 \mathrm{~K} / 4 \mathrm{E}-\mathrm{BP} 1$ pathway. Other mechanisms included TF3-mediated inactivation of Akt/c-Myc and Notch-1/c-Myc pathways. MAPK pathways were not involved. This study provides novel perspectives and potential targets for the anticancer activity of TF3 (Fig. 6). Further studies in animal models and human trials are needed to evaluate the antitumor angiogenic activity of TF3.

\section{Acknowledgements}

The authors acknowledge financial support from the West Virginia Higher Education Policy Commission/Division of Science Research. This study was also supported by NIH grants P20RR016477 from the National Center for Research Resources and P20GM103434 from the National Institute for General Medical Sciences (NIGMS) awarded to the West Virginia IDeA Network of Biomedical Research Excellence.

\section{References}

1. Mizuno T, Suzuki N, Makino H, Furui T, Morii E, Aoki H, Kunisada T, Yano M, Kuji S, Hirashima Y, et al: Cancer stem-like cells of ovarian clear cell carcinoma are enriched in the ALDH-high population associated with an accelerated scavenging system in reactive oxygen species. Gynecol Oncol 137: 299-305, 2015

2. Barakat RR, Markman M and Randall M: Principles and Practice of Gynecologic Oncology. Wolters Kluwer Health/Lippincot Williams \& Wilkins, Philadelphia, PA, 2009.

3. Jayson GC, Kohn EC, Kitchener HC and Ledermann JA: Ovarian cancer. Lancet 384: 1376-1388, 2014.

4. Folkman J, Watson K, Ingber D and Hanahan D: Induction of angiogenesis during the transition from hyperplasia to neoplasia. Nature 339: 58-61, 1989.

5. Giri S, Karakoti A, Graham RP, Maguire JL, Reilly CM, Seal S, Rattan R and Shridhar V: Nanoceria: A rare-earth nanoparticle as a novel anti-angiogenic therapeutic agent in ovarian cancer. PLoS One 8: e54578, 2013.

6. Burger RA: Overview of anti-angiogenic agents in development for ovarian cancer. Gynecol Oncol 121: 230-238, 2011.

7. Zhong H, De Marzo AM, Laughner E, Lim M, Hilton DA Zagzag D, Buechler P, Isaacs WB, Semenza GL and Simons JW: Overexpression of hypoxia-inducible factor 1alpha in common human cancers and their metastases. Cancer Res 59: 5830-5835, 1999.

8. Liang YC, Chen YC, Lin YL, Lin-Shiau SY, Ho CT and Lin JK: Suppression of extracellular signals and cell proliferation by the black tea polyphenol, theaflavin-3,3'-digallate. Carcinogenesis 20: 733-736, 1999.

9. Sajilata MG, Bajaj PR and Singhai RS: Tea polyphenols as nutraceuticals. Compr Rev Food Sci Food Saf 7: 229-254, 2008

10. Tu YY, Tang AB and Watanabe N: The theaflavin monomers inhibit the cancer cells growth in vitro. Acta Biochim Biophys Sin (Shanghai) 36: 508-512, 2004.

11. Schuck AG, Ausubel MB, Zuckerbraun HL and Babich $\mathrm{H}$ : Theaflavin-3,3'-digallate, a component of black tea: an inducer of oxidative stress and apoptosis. Toxicol In Vitro 22: 598-609, 2008.

12. Gao Y, Li W, Jia L, Li B, Chen YC and Tu Y: Enhancement of (-)-epigallocatechin-3-gallate and theaflavin-3-3'-digallate induced apoptosis by ascorbic acid in human lung adenocarcinoma SPC-A-1 cells and esophageal carcinoma Eca-109 cells via MAPK pathways. Biochem Biophys Res Commun 438: 370-374, 2013.
13. Kobayashi S, Iwai S, Tsujiyama K, Kurahashi C, Udaka Y, Sanbe T, Suzaki H and Oguchi K: Theaflavin-3,3'-digallate inhibits tube formation in cocultured endothelial cells with fibroblasts. Showa Univ J Med Sci 19: 59-72, 2007.

14. Siddiqui IA, Zaman N, Aziz MH, Reagan-Shaw SR, Sarfaraz S, Adhami VM, Ahmad N, Raisuddin S and Mukhtar H: Inhibition of CWR22Rnu1 tumor growth and PSA secretion in athymic nude mice by green and black teas. Carcinogenesis 27: 833-839, 2006.

15. Xu Y, Jin YX, Wu YY and Tu YY: Isolation and purification of four individual theaflavins using semi-preparative high performance liquid chromatography. J Liquid Chromatogr Relat Technol 33: 1791-1801, 2010.

16. Fang J, Xia C, Cao Z, Zheng JZ, Reed E and Jiang BH: Apigenin inhibits VEGF and HIF-1 expression via PI3K/AKT/p70S6K1 and HDM2/p53 pathways. FASEB J 19: 342-353, 2005.

17. García-Maceira $P$ and Mateo J: Silibinin inhibits hypoxia-inducible factor-1alpha and mTOR/p70S6K/4E-BP1 signalling pathway in human cervical and hepatoma cancer cells: Implications for anticancer therapy. Oncogene 28: 313-324, 2009.

18. Chen C, Cai S, Wang G, Cao X, Yang X, Luo X, Feng Y and $\mathrm{Hu}$ J: c-Myc enhances colon cancer cell-mediated angiogenesis through the regulation of HIF-1 $\alpha$. Biochem Biophys Res Commun 430: 505-511, 2013.

19. Asano T, Yao Y, Zhu J, Li D, Abbruzzese JL and Reddy SA: The PI 3-kinase/Akt signaling pathway is activated due to aberrant Pten expression and targets transcription factors NF-kappaB and c-Myc in pancreatic cancer cells. Oncogene 23: 8571-8580, 2004.

20. Weng AP, Millholland JM, Yashiro-Ohtani Y, Arcangeli ML, Lau A, Wai C, Del Bianco C, Rodriguez CG, Sai H, Tobias J, et al: c-Myc is an important direct target of Notch1 in T-cell acute lymphoblastic leukemia/lymphoma. Genes Dev 20: 2096-2109, 2006.

21. Huang D, Ding Y, Luo WM, Bender S, Qian CN, Kort E, Zhang ZF, VandenBeldt K, Duesbery NS, Resau JH, et al: Inhibition of MAPK kinase signaling pathways suppressed renal cell carcinoma growth and angiogenesis in vivo. Cancer Res 68: 81-88, 2008.

22. Baker JA, Boakye K, McCann SE, Beehler GP, Rodabaugh KJ, Villella JA and Moysich KB: Consumption of black tea or coffee and risk of ovarian cancer. Int J Gynecol Cancer 17: 50-54, 2007.

23. Banerjee P, Banerjee S and Mazumder S: Effect of theaflavin, A black tea extract on ovarian cancer cell line. Bombay Hosp J 53: 341-348, 2011.

24. Maity S, Ukil A, Vedasiromoni JR and Das PK: Biodistribution and pharmacokinetics of theaflavin-3,3'-digallate, the major antioxidant of black tea, in mice. Int J Pharmacol 2: 240-246, 2006.

25. Huang H, Chen AY, Rojanasakul Y, Ye X, Rankin GO and Chen YC: Dietary compounds galangin and myricetin suppress ovarian cancer cell angiogenesis. J Funct Foods 15: 464-475, 2015.

26. Chen J, Chen AY, Huang H, Ye X, Rollyson WD, Perry HE, Brown KC, Rojanasakul Y, Rankin GO, Dasgupta P, et al: The flavonoid nobiletin inhibits tumor growth and angiogenesis of ovarian cancers via the Akt pathway. Int J Oncol 46: 2629-2638, 2015.

27. Schoell WM, Pieber D, Reich O, Lahousen M, Janicek M, Guecer F and Winter R: Tumor angiogenesis as a prognostic factor in ovarian carcinoma: Quantification of endothelial immunoreactivity by image analysis. Cancer 80: 2257-2262, 1997.

28. Ciardiello F, Caputo R, Bianco R, Damiano V, Fontanini G, Cuccato S, De Placido S, Bianco AR and Tortora G: Inhibition of growth factor production and angiogenesis in human cancer cells by ZD1839 (Iressa), a selective epidermal growth factor receptor tyrosine kinase inhibitor. Clin Cancer Res 7: 1459-1465, 2001.

29. Hoeben A, Landuyt B, Highley MS, Wildiers H, Van Oosterom AT and De Bruijn EA: Vascular endothelial growth factor and angiogenesis. Pharmacol Rev 56: 549-580, 2004

30. Zhu LQ, Liu J and Ma CJ: Effect of theaflavin diagallate on anti-tumor proliferation and VEGF gene expression in lung adenocancer A549 cells. Cent S Pharm 9: 23-26, 2011.

31. Jung YD and Ellis LM: Inhibition of tumour invasion and angiogenesis by epigallocatechin gallate (EGCG), a major component of green tea. Int J Exp Pathol 82: 309-316, 2001.

32. Su YL, Leung LK, Huang Y and Chen ZY: Stability of tea theaflavins and catechins. Food Chem 83: 189-195, 2003. 
33. Yang ZY, Tu YY, Xia HL, Jie GL, Chen XM and He PM: Suppression of free-radicals and protection against $\mathrm{H}_{2} \mathrm{O}_{2}$-induced oxidative damage in HPF-1 cell by oxidized phenolic compounds present in black tea. Food Chem 105: 1349-1356, 2007.

34. Gu JW, Makey KL, Tucker KB, Chinchar E, Mao X, Pei I, Thomas EY and Miele L: EGCG, a major green tea catechin suppresses breast tumor angiogenesis and growth via inhibiting the activation of HIF-1 $\alpha$ and NFxB, and VEGF expression. Vasc Cell 5: 9, 2013

35. Zhang Q, Tang X, Lu Q, Zhang Z, Rao J and Le AD: Green tea extract and (-)-epigallocatechin-3-gallate inhibit hypoxia- and serum-induced HIF-1alpha protein accumulation and VEGF expression in human cervical carcinoma and hepatoma cells. Mol Cancer Ther 5: 1227-1238, 2006.

36. Li W, Tan D, Zhang Z, Liang JJ and Brown RE: Activation of Akt-mTOR-p70S6K pathway in angiogenesis in hepatocellular carcinoma. Oncol Rep 20: 713-719, 2008.

37. Li G, Shan C, Liu L, Zhou T, Zhou J, Hu X, Chen Y, Cui H and Gao N: Tanshinone IIA inhibits HIF-1 $\alpha$ and VEGF expression in breast cancer cells via mTOR/p70S6K/RPS6/4E-BP1 signaling pathway. PLoS One 10: e0117440, 2015.

38. Xu Q, Liu LZ, Qian X, Chen Q, Jiang Y, Li D, Lai L and Jiang BH: MiR-145 directly targets p70S6K1 in cancer cells to inhibit tumor growth and angiogenesis. Nucleic Acids Res 40: 761-774, 2012.

39. Pratheeshkumar P, Budhraja A, Son YO, Wang X, Zhang Z, Ding S, Wang L, Hitron A, Lee JC, Xu M, et al: Quercetin inhibits angiogenesis mediated human prostate tumor growth by targeting VEGFR- 2 regulated AKT/mTOR/P70S6K signaling pathways. PLoS One 7: e47516, 2012.

40. Baudino TA, McKay C, Pendeville-Samain H, Nilsson JA, Maclean KH, White EL, Davis AC, Ihle JN and Cleveland JL: $\mathrm{c}-\mathrm{Myc}$ is essential for vasculogenesis and angiogenesis during development and tumor progression. Genes Dev 16: 2530-2543, 2002.

41. Lee JG and Wu R: Erlotinib-cisplatin combination inhibits growth and angiogenesis through c-MYC and HIF-1 $\alpha$ in EGFRmutated lung cancer in vitro and in vivo. Neoplasia 17: 190-200, 2015.

42. Meng RD, Shelton CC, Li YM, Qin LX, Notterman D, Paty PB and Schwartz GK: gamma-Secretase inhibitors abrogate oxaliplatin-induced activation of the Notch-1 signaling pathway in colon cancer cells resulting in enhanced chemosensitivity. Cancer Res 69: $573-582,2009$

43. Garcia A and Kandel JJ: Notch: A key regulator of tumor angiogenesis and metastasis. Histol Histopathol 27: 151-156, 2012.

44. Guo D, Li C, Teng Q, Sun Z, Li Y and Zhang C: Notch1 overexpression promotes cell growth and tumor angiogenesis in myeloma. Neoplasma 60: 33-40, 2013.

45. Proia T, Jiang F, Bell A, Nicoletti R, Kong L, Kreuter K, Poling L, Winston WM, Flaherty M, Weiler S, et al: 23814, an inhibitory antibody of ligand-mediated Notch1 activation, modulates angiogenesis and inhibits tumor growth without gastrointestinal toxicity. Mol Cancer Ther 14: 1858-1867, 2015.
46. Yan B, Zhou Y, Feng S, et al: beta-elemene-attenuated tumor angiogenesis by targeting Notch-1 in gastric cancer stem-like cells. J Evid Based Complementary Altern Med 2013: 268468, 2013.

47. Rose SL, Kunnimalaiyaan M, Drenzek J and Seiler N: Notch 1 signaling is active in ovarian cancer. Gynecol Oncol 117: 130-133, 2010.

48. Shankar S, Chen Q and Srivastava RK: Inhibition of PI3K/AKT and MEK/ERK pathways act synergistically to enhance antiangiogenic effects of EGCG through activation of FOXO transcription factor. J Mol Signal 3: 7, 2008.

49. Potente M, Urbich C, Sasaki K, Hofmann WK, Heeschen C, Aicher A, Kollipara R, DePinho RA,Zeiher AM and Dimmeler S: Involvement of Foxo transcription factors in angiogenesis and postnatal neovascularization. J Clin Invest 115: 2382-2392, 2005.

50. Asada S, Daitoku H, Matsuzaki H, Saito T, Sudo T, Mukai H, Iwashita S, Kako K, Kishi T, Kasuya Y, et al: Mitogen-activated protein kinases, Erk and p38, phosphorylate and regulate Foxo1. Cell Signal 19: 519-527, 2007.

51. Lam EW, Francis RE and Petkovic M: FOXO transcription factors: Key regulators of cell fate. Biochem Soc Trans 34: 722-726, 2006

52. Jung YD, Kim MS, Shin BA, Chay KO, Ahn BW, Liu W, Bucana CD, Gallick GE and Ellis LM: EGCG, a major component of green tea, inhibits tumour growth by inhibiting VEGF induction in human colon carcinoma cells. Br J Cancer 84: 844-850, 2001

53. Shankar S, Marsh L and Srivastava RK: EGCG inhibits growth of human pancreatic tumors orthotopically implanted in Balb C nude mice through modulation of FKHRL1/FOXO3a and neuropilin. Mol Cell Biochem 372: 83-94, 2013.

54. Wang F, Chang Z, Fan Q and Wang L: Epigallocatechin-3-gallate inhibits the proliferation and migration of human ovarian carcinoma cells by modulating p38 kinase and matrix metalloproteinase-2. Mol Med Rep 9: 1085-1089, 2014.

55. Jhoo JW, Lo CY, Li S, Sang S, Ang CY, Heinze TM and Ho CT: Stability of black tea polyphenol, theaflavin, and identification of theanaphthoquinone as its major radical reaction product. J Agric Food Chem 53: 6146-6150, 2005.

56. Sang S, Lambert JD, Tian S, Hong J, Hou Z, Ryu JH, Stark RE, Rosen RT, Huang MT, Yang CS, et al: Enzymatic synthesis of tea theaflavin derivatives and their anti-inflammatory and cytotoxic activities. Bioorg Med Chem 12: 459-467, 2004.

57. Park HY, Kunitake Y and Matsui T: Benzotropolone moiety in theaflavins is responsible for inhibiting peptide-transport and activating AMP-activated protein kinase in Caco-2 cells. Funct Foods Health Dis 3: 111-121, 2013. 